\title{
USE OF PCR-RFLP OF THE FLA A GENE FOR DETECTION AND SUBTYPING OF CAMPYLOBACTER JEJUNI STRAINS POTENTIALLY RELATED TO GUILLAIN-BARRÉ SYNDROME, ISOLATED FROM HUMANS AND ANIMALS
}

\author{
Scarcelli, E. ; ${ }^{1}$ Piatti, R.M. ; Harakava, R. ; Miyashiro, S. ${ }^{1}$; Campos, F.R. ; Souza, M.C.A. ; Cardoso, M.V. ${ }^{1}$; Teixeira, \\ ${ }^{1}$; Genovez, M.E. ${ }^{1}$
}

${ }^{1}$ Centro de Pesquisa e Desenvolvimento de Sanidade Animal, Instituto Biológico, São Paulo, SP, Brasil; ${ }^{2}$ Centro de Pesquisa e Desenvolvimento de Sanidade Vegetal, Instituto Biológico, São Paulo, SP, Brasil; ${ }^{3}$ Agência Paulista de Tecnologia dos Agronegócios, Pólo Regional do Vale do Paraíba, Unidade de Pesquisa e Desenvolvimento de Pindamonhangaba,

Pindamonhangaba, SP, Brasil.

Submitted: September 05, 2008; Returned to authors for corrections: November 12, 2008; Approved: May 15, 2009.

\begin{abstract}
The objectives of the present study were the subtyping of Campylobacter jejuni subsp. jejuni strains obtained from humans and different animal species using PCR-RFLP, and the detection, by means of the same technique, of strains related to serotype PEN O19:LIO 7, the main C. jejuni serotype linked to Guillain-Barré Syndrome (GBS). Seventy C. jejuni strains isolated from human feces (n=33), primates $(n=15), \operatorname{dogs}(n=5)$, swine $(n=2)$, bovines $(n=1)$, abortion material from goats $(n=2)$ and poultry carcasses $(n=12)$, all collected in the state of São Paulo, were subtyped by means of PCR-RFLP of fla A gene, using restriction endonucleases Hae III, Afa I and Mbo I. Seven subtypes were observed when using the enzyme Hae III; eight when using Mbo I; and seven when using Afa I. The combination of the three endonucleases led to 16 fla-RFLP subtypes, from which ten subtypes shared strains of human and animal origin. From these, seven subtypes were observed in human and broiler strains. In eight subtypes, the other animal species shared patterns with human strains. It was inferred that, besides broilers, swine, goats, dogs and primates may be sources of infection for human in São Paulo. PCR-RFLP is a highly discriminatory technique that may be applied to molecular epidemiology studies of samples from different origins. Besides, the study also enabled the detection of two human strains and two primate strains related to serotype PEN O19: LIO 7.
\end{abstract}

Key words: Campylobacter jejuni, PCR-RFLP, subtyping, Guillain-Barré Syndrome

\section{INTRODUCTION}

Campylobacter jejuni subsp. jejuni is the most common cause of diarrhea in children in developing countries and the primary cause of enterites in industrialized regions $(4,27)$. Although recognized as an important pathogen for more than 20 years, its epidemiology is only partially understood (14), mainly in Brazil. 
The internal variability observed in the flagelin gene sequence has been used as a base for $C$. jejuni subtyping methods, such as PCR-RFLP and sequencing $(17,24)$. The fla A gene has been frequently used in epidemiological studies in order to determine $C$. jejuni subtypes that may be involved in outbreaks, or even in sporadic cases of food borne disease $(8,11,24)$.

During the last few years, an association between $C$. jejuni infection and two neurological emergent diseases has been demonstrated: Guillain-Barré Syndrome (GBS) and Muller-Fisher Syndrome (MFS), a rare GBS variant $(9,10)$. GBS is mostly characterized by acute inflammatory demyelinization of the peripheral nervous system (12). In serological studies, it has been observed that $40 \%$ of the GBS patients showed recent infection by $C$. jejuni, mainly associated with serotype PENO19:LIO 7 (1, 2, 20). Dourado et al.(7) demonstrated in Rio Grande do Norte, Brazil, an association between GBS and the detection of antibodies anti-Campylobacter jejuni and anti-gangliosides (GM1).

The objectives of the present study were the subtyping of different Campylobacter jejuni subsp. jejuni strains isolated from humans and different animal species using PCR-RFLP, and to detect, by means of this technique, strains related to serotype PEN O19: LIO 7, in the state of São Paulo.

\section{MATERIALS AND METHODS}

Thirty seven Campylobacter jejuni strains, previously isolated from bacteriological analysis (23) of 1,094 biological samples from different animal species and several locations in the state of São Paulo, were received in the Laboratório de Doenças Bacterianas da Reprodução at Instituto Biológico. Other 33 C. jejuni strains of human origin, isolated from adults and children affected by diarrhea, were also studied. These feces samples were analyzed in clinical laboratories in the city of São Paulo (Table 1). The reference strain used was Campylobacter jejuni subsp. jejuni Lior 7, from the National Enteric Reference Centre, Laboratory Center for Disesases Control, Ottawa, Ontario, Canada, serotype LIO 7, according to the classification by Lior et al. (16).

Table 1. List of the 70 C. jejuni field strains used in PCR-RFLP of fla A gene.

\begin{tabular}{ccc}
\hline Sample source (type of sample) & Total of samples & Strain denominations \\
\hline Bovines (feces) & 1 & B1 \\
Swine (feces) & 2 & S1- S2 \\
Dogs (feces) & 5 & D1-D5 \\
Poultry (carcass) & 12 & P1-P12 \\
Monkeys (feces) & 15 & M1-M15 \\
Caprines (aborted fetuses) & 2 & CAPR1-CAPR2 \\
Humans (feces) & 33 & H1-H33 \\
\hline
\end{tabular}

\section{DNA preparation and PCR of fla A gene}

C. jejuni strains were grown at $37^{\circ} \mathrm{C}$ for $48 \mathrm{~h}$ under microerophilic atmosphere $\left(5 \% \mathrm{CO}_{2}\right)$ on blood Brucella agar (Difco-BBL). DNA was extracted by boiling, according to Nishimura et al. (18) and On et al. (19). Colonies obtained from 2 to 3 day-old cultures were used to prepare $C$. jejuni suspensions in $1.0 \mathrm{~mL}$ of ultrapure water (Milli-Q, Millipore Inc.), corresponding to 8 on the McFarland turbidity scale $\left(2.3 \times 10^{9} \mathrm{bact} / \mathrm{mL}\right)$. These suspensions were heated at $100^{\circ} \mathrm{C}$ for $10 \mathrm{~min}$. Five microliters of the suspension supernatant were used as templates. The oligonucleotides used as PCR primers were forward fla A primer 5'-TA CTA CAG GAG 
TTC AAG CTT-3' and reverse fla A primer 5'-GT TGA TGT AAC TTG ATT TTG-3' that represented the variable (V1) region, according to Nishimura et al. (18). PCR was performed with $1 \times$ PCR buffer (Invitrogen), $200 \mu \mathrm{M}$ dNTPs, $2.5 \mathrm{mM} \mathrm{MgCl} 2,40$ pmol of each primer, $2.5 \mathrm{u}$ Taq DNA polymerase (Invitrogen), and $5 \mu 1$ DNA template. A 30-cycle reaction was run in a PTC 200 thermocycler (MJ Research) with $48 \mathrm{sec}$ denaturing at $94^{\circ} \mathrm{C}, 36 \mathrm{sec}$ annealing at $55^{\circ} \mathrm{C}, 2$ min extension at $72^{\circ} \mathrm{C}$ and $10 \mathrm{~min}$ final extension at $72^{\circ} \mathrm{C}$. The resulting product was approximately $702 \mathrm{bp}$. The amplified product from gene fla A was analyzed by means of $2.0 \%$ agarose gel electrophoresis in $0.5 \mathrm{X}$ TBE buffer (0.045M TRIS-Borate and 1mM EDTA, pH 8.0). The gel was submitted to constant voltage equal to $5-6 \mathrm{~V} / \mathrm{cm}$, using a 100bp ladder as the standard marker (Invitrogen). Gel was stained with ethidium bromide $0.5 \mu \mathrm{g} / \mathrm{mL}$, for $15 \mathrm{~min}$ and photographed under UV light (300-320nm) using a Kodak Digital Camera DC/120 Zoom. Images were analyzed by the 1D Image Analysis software (Kodak Digital Science).

\section{PCR-RFLP}

After amplification, DNA products were digested with restriction enzymes Hae III, Mbo I and Afa I (BioAgency $\mathrm{BR})$. The reaction was carried out in a final volume equal to $20 \mu \mathrm{L}$ for each enzyme containing; enzyme buffer, $6 \mu \mathrm{L}$ amplified product and $10 \mathrm{U}$ of enzyme, and was incubated for $3 \mathrm{~h}$ at $37^{\circ} \mathrm{C}(18)$. The digested product was analyzed by means of $3.0 \%$ agarose gel electrophoresis, using the same procedure described above.

\section{RESULTS}

PCR-RFLP using restriction endonuclease Hae III, applied to the 70 strains isolated and to the Lior 7 reference strain, produced 7 different restriction patterns, as shown in Table 2 and in Figure 1a.

PCR-RFLP applied to 70 strains and to the reference strain, using restriction endonuclease $M b o$ I, produced 8 different restriction patterns, as presented in Table 3 and Figure 1b.

PCR-RFLP applied to 70 strains and to the reference strain Lior 7, using restriction endonuclease Afa I, produced 7 different restriction patterns, as presented in Table 4 and Figure 1c.

The combination of the three restriction endonucleases Hae III, Mbo I and Afa I - applied to the $70 C$. jejuni strains and to the reference strain Lior 7, showed 16 different $C$. jejuni subtypes differentiated by PCR-RFLP, as shown in Table 5. The procedure showed high heterogeneity between the subtypes.

Table 2. Restriction patterns of 70 Campylobacter jejuni strains, and the reference strain, obtained using restriction endonuclease Hae III applied to PCR-amplified 702 pb fragment of fla A gene.

\begin{tabular}{|c|c|}
\hline $\begin{array}{c}\text { PCR-RFLP } \\
\text { Hae III Pattern }\end{array}$ & Strain denominations \\
\hline Pattern 1 & $\begin{array}{c}\text { P3, P5, P6, P7, P10, H4, H6, H8, H12, H13, H14, H15, H22, H23, H26, H27, } \\
\text { H28, H30, H32, H33, M6, M11, Capr1, Capr2 }\end{array}$ \\
\hline Pattern 2 & $\begin{array}{c}\mathrm{P} 1, \mathrm{P} 2, \mathrm{P} 4, \mathrm{P} 11, \mathrm{P} 12, \mathrm{H} 1, \mathrm{H} 2, \mathrm{H} 3, \mathrm{H} 9, \mathrm{H} 10, \mathrm{H} 11, \mathrm{H} 18, \mathrm{H} 19, \mathrm{H} 20, \mathrm{H} 24, \mathrm{H} 25, \\
\mathrm{H} 29, \mathrm{M} 1, \mathrm{M} 2, \mathrm{M} 3, \mathrm{M} 7, \mathrm{M} 8, \mathrm{D} 1, \mathrm{D} 2, \mathrm{D} 3, \mathrm{D} 4, \mathrm{D} 5, \mathrm{~B} 1\end{array}$ \\
\hline Pattern 3 & $\mathrm{H} 16$ \\
\hline Pattern 4 & H5, H7, P5, P15, Lior 7 \\
\hline Pattern 5 & P8, P9, H17, H21, H31, S1, S2 \\
\hline Pattern 6 & M4, M13, M14 \\
\hline Pattern 7 & M9, M10, M12 \\
\hline
\end{tabular}

$\mathrm{B}=$ Bovine, $\mathrm{D}=$ Dog, $\mathrm{P}=$ Poultry, $\mathrm{H}=$ Human, $\mathrm{M}=$ Monkey, $\mathrm{S}=$ Swine, Capr=Caprine, Lior $7=$ reference strain 
Table 3. Restriction patterns of 70 Campylobacter jejuni strains, and the reference strain, obtained using restriction endonuclease $M b o$ I applied to PCR-amplified $702 \mathrm{pb}$ fragment of fla A gene.

\begin{tabular}{|c|c|}
\hline $\begin{array}{c}\text { PCR-RFLP } \\
\text { Mbo I Pattern }\end{array}$ & Strain denominations \\
\hline Pattern 1 & $\begin{array}{c}\text { P1, P2, P7, P8, P9, P11, H4, H9, H10, H11, H13, H15, H16, H17, H19, H20, } \\
\text { H22, H23, H24, H25, H26, H28, H29, H30, H33, M7, M9, B1, D1, D5, S1, } \\
\text { S2, Capr1, Capr2 }\end{array}$ \\
\hline Pattern 2 & $\mathrm{H} 18, \mathrm{M} 1, \mathrm{M} 2, \mathrm{M} 3, \mathrm{D} 2, \mathrm{D} 4$ \\
\hline Pattern 3 & H1, H2, D3, H5, H7, H8, H33, M5, M15, Lior 7 \\
\hline Pattern 4 & P4, P5, P6, P12, H3, H6, H12, H14, H32, M8 \\
\hline Pattern 5 & M4, M13, M14 \\
\hline Pattern 6 & P3, P10, H27, M6, M11 \\
\hline Pattern 7 & $\mathrm{H} 21$ \\
\hline Pattern 8 & M10, M12 \\
\hline
\end{tabular}

Table 4. Restriction patterns of 70 Campylobacter jejuni strains, and the reference strain, obtained using restriction endonuclease $A f a$ I applied to PCR-amplified $702 \mathrm{pb}$ fragment of fla A gene.

\begin{tabular}{|c|c|}
\hline $\begin{array}{l}\text { PCR-RFLP } \\
\text { Afa I Pattern }\end{array}$ & Strain denominations \\
\hline Pattern 1 & $\begin{array}{c}\text { P1, P2, P3, P4, P5, P8, P9, P10, P11, P12, H3, H6, H9, H10, H11, H14, } \\
\text { H16, H17, H19, H20, H21, H24, H25, H27, H22, H23, H31, M6, M7, } \\
\text { M8, M9, M14, D1, D5, S1, S2 }\end{array}$ \\
\hline Pattern 2 & M4, M13, B1 \\
\hline Pattern 3 & $\begin{array}{c}\text { P6, P7, H1, H2, H4, H12, H13, H15, H26, H28, H29, H30, H32, D3, } \\
\text { Capr1, Capr2 }\end{array}$ \\
\hline Pattern 4 & M11 \\
\hline Pattern 5 & $\mathrm{H} 18, \mathrm{M} 1, \mathrm{M} 2, \mathrm{M} 3, \mathrm{D} 2, \mathrm{D} 4$ \\
\hline Pattern 6 & M10, M12, \\
\hline Pattern 7 & H5, H7, H8, M5, M15, H33, Lior 7 \\
\hline
\end{tabular}

$\begin{array}{lllllllll}M & 1 & 2 & 3 & 4 & 5 & 6 & 7 & 8\end{array}$

$\begin{array}{llllllll}1 & 2 & 3 & 4 & 5 & 6 & 7 & M\end{array}$

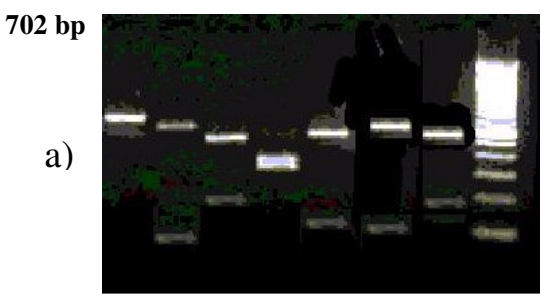

702 bp

b)
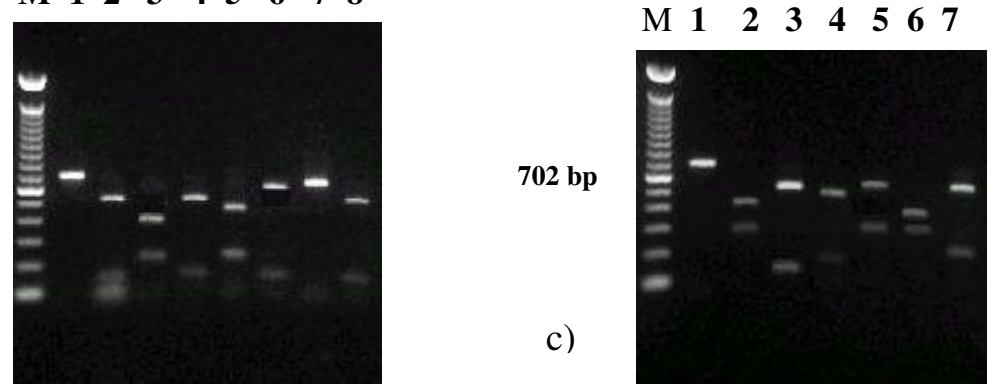

Figure 1. Representative restriction endonuclease digests of PCR-amplified 702 bp fragment of Campylobacter jejuni fla A gene. RFLP patterns were as follows: seven Hae III patterns, lanes 1-7, respectively (a); eight Mbo I patterns, lanes 1-8, respectively (b); seven Afa I patterns, lanes 1-7 respectively (c). Lane M: 100 bp DNA Ladder (Invitrogen). 
Table 5. Subtypes based on the combination of the restriction profiles obtained with the three restriction endonucleases used, Hae III, Mbo I and Afa I, applied to the 70 Campylobacter jejuni strains and to the reference strain Lior 7.

\begin{tabular}{|c|c|}
\hline $\begin{array}{c}\text { RFLP Subtypes } \\
(\text { Hae III, Mbo I and Afa I) }\end{array}$ & Strain denominations \\
\hline fla-RFLP 1 & $\begin{array}{c}\text { D1 D5 P1 P2 P11 H9 H10 H11 H19 H20 H24 } \\
\text { H25 M7 }\end{array}$ \\
\hline fla -RFLP 2 & $\begin{array}{c}\text { D2 D4 M1 M2 M3 M10 M12 } \\
\text { M13 H18 }\end{array}$ \\
\hline fla-RFLP 3 & P7 H4 H13 H15 H26 H28 H30 M11 Capr1 Capr2 \\
\hline fla-RFLP 4 & P8 P9 H17 H21 H31 S1 S2 \\
\hline fla-RFLP 5 & P4 P12 H3 M4 M8 M14 \\
\hline fla-RFLP 6 & P5 H6 H14 M6 \\
\hline fla-RFLP 7 & H5 H7 M5 M15 Lior 7 \\
\hline fla-RFLP 8 & H1 H2 D3 \\
\hline fla-RFLP 9 & P3 H27 P10 \\
\hline fla-RFLP 10 & P6 H12 H32 \\
\hline fla-RFLP 11 & H22 H23 \\
\hline fla-RFLP 12 & H16 \\
\hline fla-RFLP 13 & M9 \\
\hline fla-RFLP 14 & H8 H33 \\
\hline fla-RFLP 15 & B1 \\
\hline fla-RFLP 16 & $\mathrm{H} 29$ \\
\hline
\end{tabular}

Table 5 shows that the combination of the three restriction endonucleases produced 16 fla-RFLP subtypes. From these, four subtypes comprised only strains of human origin (fla-RFLP 11, 12, 14 and 16); two subtypes (fla-RFLP 13 and 15) involved only strains of animal origin and the other subtypes shared human and animal strains. The subtypes fla-RFLP 1, 3, 4, 5, 6, 9 and 10 comprised human and poultry strains and the subtypes fla-RFLP 1, 2, 3, 4, 5, 6, 7 and 8 the other animal species shared patterns with human strains.

Subtype fla-RFLP 1 was the most frequent one, involving $13(18,6 \%)$ from the 70 field strains analyzed, followed by subtype fla-RFLP 2 with $9(12,8 \%)$ and flaRFLP 3, with 10 (14.3\%) strains, and by subtype fla- RFLP 4 , with seven strains $(10 \%)$. The other strains were grouped in the 12 remaining subtypes (fla-RFLP 5 and 16), ranging from one to six strains per subtype (Table 5).

\section{Detection of serotype PENO19:LIO:7 using PCR-RFLP}

Serotype PENO19:LIO:7 was detected by means of PCR-RFLP in the reference strain Lior 7 and in four $C$. jejuni strains: two human strains (H5 and H7) and two strains from primates (M5 and M15). Restriction pattern of fla-RFLP 7 (Table 5) obtained by the combination of the enzymes Hae III (Pattern 4), Mbo I (Pattern 3) and Afa I (Pattern 7) corresponded to subtype $\mathrm{Cj}-1$, described by Nishimura et al. (18) as the molecular standard significantly associated with serotype PENO19:LIO 7 (18, 26).

\section{DISCUSSION}

Bacteria in the Campylobacteraceae family are not frequently studied in microbiological routine. They are microaerophylic, adding a limiting factor for their isolation and to the systematic study of the epidemiology of different species and subtypes in the genus Campylobacter, mainly 
clinical strains $(13,14,22)$. Besides, the genus has great public health importance because it involves several diarrheacausing species (5).

In the comparison of $C$. jejuni strains obtained from different animal species and human strains previously isolated in clinical laboratories in the city of São Paulo, PCRRFLP showed that several human strains could be differentiated in distinct patterns or subtypes and grouped with strains from different animal species (Tables 2, 3 and 4).

In the present study, the $12 C$. jejuni strains isolated from poultry were grouped with human strains in seven of the 16 subtypes generated by PCR-RFLP (Table 5).

The five $C$. jejuni strains isolated from dogs were grouped with human strains by PCR-RFLP in three subtypes. These animals were considered to be sources of $C$. jejuni infection for the group of humans studied.

The only bovine strain analyzed showed an exclusive PCR-RFLP pattern (fla-RFLP 15) and was not grouped with any human strain. In Europe and the United States, Campylobacter jejuni is responsible for sporadic outbreaks of intestinal campylobacteriosis $(3,21)$, with bovines playing a significant role as sources of human campylobacteriosis (Saito et al., 2005). According to Saito et al.(21), in Japan, the importance of bovines as sources of $C$. jejuni infection have not been totally elucidated, but studies indicate that a large proportion of bovines bred in Japan are intestinal carriers of $C$. jejuni. This fact would facilitate the occurrence of cross contamination in this country, once bovine liver and intestines are popular items in certain restaurants.

PCR-RFLP grouped samples common to poultry, humans and primates in four subtypes each. It should be considered that poultry meat was part of the diet of these animals, and may have been the source of infection for them.

The subtyping study showed that two strains isolated from two aborted goat fetuses from the same farm presented identical restriction patterns (fla-RFLP 3), indicating that the contamination of the two animals came from a common source. It should also be emphasized that goat strains were grouped with human strains, showing that this species may also be a source of human infection.

Due to the diversity of patterns grouping human strains with those of different animal origins, it may be observed that the source of Campylobacter spp. for humans was not restricted to poultry, in samples collected in the state of São Paulo. Swine, goats, dogs and primates may also be sources of human infection in our state.

Similar results were obtained by Nishimura et al. (18), using for the first time a combination of the same restriction endonucleases in PCR-RFLP of a $702 \mathrm{pb}$ fragment of fla A gene. These authors observed 25 distinct patterns for $154 C$. jejuni strains obtained from humans in China and Japan. Steinhauserova et al (25), in the Czech Republic, using the same fragment of fla A gene and the same enzymes, showed 22 patterns in 156 C. jejuni samples from humans and poultry. Tsai et al.(26), in Taiwan, obtained 45 different PCR-RFLP patterns using a combination of the three enzymes for the analysis of Campylobacter jejuni from 220 strains obtained from humans, poultry and dogs.

In the present study, in spite of the analysis of a greater diversity of animals, the number of patterns $(n=16)$ was not substantially greater that observed by other authors $(18,25$, 26).

Nishimura et al.(18) showed a correlation between PCRRFPL and serotyping of strains from patients presenting Guillain-Barré Syndrome (GBS) and carrying serotype PENO19:LIO 7. These authors concluded that PCR-RFLP analysis for $C$. jejun may not only contribute for epidemiological subtyping studies, but also for the analysis of C. jejuni subtypes related to GBS.

In the present study, it was observed that subtype flaRFLP 7 was grouped together with reference strain Lior 7, corresponding to serotype PENO19:LIO 7, two human strains (H5 and H7) and two primate strains (M5 and M15). Patterns obtained for these strains by means of the three restriction enzymes were similar to those observed by Nishimura et al. (18) in Japan and China, for human strains, 
Scarcelli, E. et al.

and by Tsai et al. (26) in Taiwan, for dog strains. Therefore, the presence of serotype PENO19:LIO 7, main serotype related to Guillain-Barré Syndrome (GBS), was demonstrated in the state of São Paulo.

Control and prevention strategies may not be developed and implemented without the adequate understanding of campylobacteriosis (14).

PCR-RFLP of fla A gene demands less equipment when compared with other subtyping techniques, such as sequencing and PFGE $(6,15)$. Besides, it is a simple, cheap and simple technique for the subtyping of Campylobacter jejuni strains and it is discriminatory enough to be applied to molecular epidemiology studies in samples isolated from different origins. Therefore, it is feasible to be used in human and veterinary laboratories $(8,14)$, enabling the detection of serotype PENO19:LIO 7 strains associated with GBS (Nishimura et al. 1996).

\section{ACKNOWLEDGEMENTS}

This study was financially supported by FAPESP Fundação de Amparo a Pesquisa do Estado de São Paulo research project \# 2003/10776-4.

We thank Dra. Angela Cristina Rodrigues Ghilardi, from the Seção de Bacteriologia, Instituto Adolfo Lutz, São Paulo, SP, Brazil, for donation of the reference strain Lior 7.

\section{REFERENCES}

1. Allos, B.M. (1997). Association between Campylobacter infection and Guillain-Barré syndrome. J. Infect. Dis. 176 (2), 125-128.

2. Allos, B.M.; Lippy, F.T.; Carlsen, A.; Washburn, R.G.; Blaser, M.J. (1998). Campylobacter jejuni strains from patients with Guillain-Barré syndrome. Emerg. Infect. Dis. 4 (2), 263-268.

3. Altekruse, S.F.; Swerdlow, D.L.; Stern, N.J. (1998). Microbial food borne pathogens. Campylobacter jejuni. Vet. Clin. North Am. Food Anim. Pract., Review. 14 (1), 31-40.

4. Carvalho, A.C.T.; Ruiz-Palacios, G.M.; Ramos-Cervantes, P.; Cervantes, L.; Jing, X.; Picckering, L.K. (2001). Molecular characterization of invasive and noninvasive Campylobacter jejuni and Campylobacter coli isolates. J. Clin. Microbiol. 39 (4), 1353-1359.
5. Cortez, A.L.L.; Carvalho, A.C.F.B.; Scarcelli, E.; Miyashiro, S.; Vidal Martins, A.M.C.; Burger, K.P. (2006). Survey of chicken abattoir for the presence of Campylobacter jejuni and Campylobacter coli. Rev. Inst. Med. Trop. S. Paulo, 48 (6), 307-310.

6. Desai, M.; Logan, J.M.J.; Frost, J.A.; Stanley, J. (2001). Genome sequence-based fluorescent length polymorphism of Campylobacter jejuni, its relationship to serotyping, and its implications for epidemiological analysis. J. Clin. Microbiol. 39 (11), 3823-3829.

7. Djordjevic, S.P.; Unicomb, L.E.; Adamson, P.J.; Mickan, L.; Rios, R. (2007). The Australian Campylobacter Subtyping Study Group. Clonal Complexes of Campylobacter jejuni identified by Multilocus Sequence Typing are reliably predicted by Restriction Fragment Length Polymorphism analyses of the fla A gene. J. Clin. Microbiol. 45 (1), 102-108.

8. Dourado, M.E.; Duarte, R.C.; Ferreira, L.C.; Queiroz, J.W.; Illa, I.; Perez-Perez, G.; Guerrant, R.L.; Jerônimo, S.M.B. (2003). Antiganglioside antibodies and clinical outcome of patients with GuillainBarré Syndrome in northeast Brazil. Acta Neurol. Scand. 108, (2), 102108.

9. Duim, B.; Win Ang, C.; Van Bellkum, A.; Rigter, A.; Van Leeuwen, N.W.J.; Endtz, H.P.; Wagenaar, J.A. (2000). Amplified fragment length polymorphism analysis of Campylobacter jejuni strains isolated from chickens and patients with gastroenteritis or Guillain-Barré or Miller Fisher syndrome. Appl. Environ. Microbiol. 66 (9), 3917-3923.

10. Endtz, H.P.; Ang, C.W.; Van Den Braak, N.; Duim, B.; Rigter, A.; Price, L.J.; Woodward, D.L.; Rodgers, F.G.; Johnson, W.M.; Wagenaar, J.A.; Jacobs, B.C.; Verbrugh, H.A.; Van Belkum, A. (2000). Molecular characterization of Campylobacter jejuni from patients with Guillain-Barre and Miller Fisher syndromes. J. Clin. Microbiol. 38 (6), 2297-2301.

11. Fitzgerald, C.; Helsel, L.O.; Nicholson, M.A.; Olsen, S.J.; Swerdlow, D.L.; Flahart, R.; Sexton, J.; Fields, P.I. (2001). Evaluation of methods for subtyping Campylobacter jejuni during an outbreak involving a food handler. J. Clin. Microbiol. 39 (7), 2386-2390.

12. Fujimoto, S.; Yuki, N.; Itoh, T.; Amako, K. (1992). Specific serotype of Campylobacter jejuni associated with Guillain-Barre syndrome. J. Infect. Dis. 165 (1), 183.

13. Giacoboni, G.; Echeverría, M.G.; Perfumo, C. (2005). PCR-RFLP for Campylobacter jejuni subtyping. Rev. Argent. Microbiol. 37 (2), 81-83.

14. Gillespie, I.A.; O'Brien, S.J.; Frost, J.A.; Adak, G.K.; Horby, P.; Swan, A.V.; Painter, M.J.; Neal, K.R. (2002). The Campylobacter Sentinel Surveillance Scheme Collaborators. A Case-Case Comparison of Campylobacter coli and Campylobacter jejuni Infection: A Tool for Generating Hypotheses. Emerg. Infect. Dis. 8 (9), 937-942.

15. Kéller, J.; Wieland, B.; Wittwer, M.; Stepphan, R.; Perreten, V. (2007). Distribution and genetic variability among Campylobacter spp. isolates from different animal species and humans in Switzerland. Zoon. Public Health. 54, 2-7. 
16. Lior, H.; Woodward, D.L.; Edgar, J.A.; Laroche, L.J.; Gill, P. (1982). Serotyping of Campylobacter jejuni by slide agglutination based on heat-labile antigenic factors. J Clin Microbiol, 15 (5), 761-768.

17. Meinersmann, R.J.; Helsel, L.O.; Fields, P.I.; Hiett, K.L. (1997). Discrimination of Campylobacter jejuni isolates by fla gene sequencing. J. Clin. Microbiol, 35 (11), 2810-2814.

18. Nishimura, M.; Nukina, M.; Yuan, J.M.; Shen, B.Q.; M.A.J.J.; Ohta, M.; Saida, T.; Uchiyama, T. (1996). PCR-based restriction fragment length polymorphism (RFLP) analysis and serotyping of Campylobacter jejuni isolates from diarrheic patients in China and Japan. FEMS Microbiol. Lett. 142 (2-3), 133-138.

19. On, S.; Harrington, C.S. (2001). Evaluation of numerical analysis of PFGE-DNA profiles for differentiating Campylobacter fetus subspecies by comparison with phenotypic, PCR and $16 \mathrm{~S}$ rDNA sequencing methods. J. Appl. Micrbiol. 90 (2), 285-293.

20. Saida, T.; Kuroki, S.; Hao, Q.; Nishimura, M.; Nukina, M.; Obayashi, H. (1997). Campylobacter jejuni isolates from Japanese patients with Guillain-Barré syndrome. J. Infect. Dis. 176 (2), 129-134.

21. Saito, S.; Yatsuyanagi, J.; Harata, S.; Ito, Y.; Shinagawa, K.; Suzuki, N.; Amano, K.; Enomoto, K. (2005). Campylobacter jejuni isolated from retail poultry meat, bovine feces and bile, and human diarrheal samples in Japan: comparison of serotypes and genotypes. FEMS Immunol. Med. Microbiol. 45 (2), 311-319.

22. Sanz, J.C.; Rios, R.R.; Lopez-Portoles, J.A.; Taveira, J.A.; Simon, C.;
Echeita, M.A. (2006). Descripción de um brote de gastroenteritis por Campylobacter jejuni y caracterización molecular de la cepa implicada. Enferm. Infecc. Microbiol. Clin. 24 (7), 437-439.

23. Scarcelli, E.; Genovez, M.E.; Cardoso, M.V.; Souza, M.C.A.M.; Grasso, L.M.P.S.; Souza, C.A.I.; Torres, A.P. (1998). Avaliação do potencial de disseminação de Campylobacter spp por diferentes espécies animais. Arq Inst Biol. 65 (1), 55-61,

24. Scarcelli, E.; Piatti, R.M.; Harakava, R.; Miyashiro, S.; Campos Fernandes, F.M.; Campos, F.R.; Francisco, W.; Genovez, M.E.; Richtzenhain, L.J. (2005). Molecular subtyping of Campylobacter jejuni subsp. jejuni strains isolated from different animal species in the state of São Paulo, Brazil. Braz. J. Microbiol. 36 (4), 378-382.

25. Steinhauserova, I.; Ceskova, J.; Nebola, M. (2002). PCR/Restriction fragment length polymorphism (RFLP) typing of human and poultry Campylobacter jejuni strains. Lett. Appl. Microbiol, 34 (5), 354-358.

26. Tsai, H.J.; Huang, H.C.; Tsai, H.L.; Chamg, C.C. (2006). PCR-based restriction fragment length polymorphism (RFLP) analysis of Campylobacter jejuni isolates from humans, chickens and dogs in northern Taiwan. J. Vet. Med. Sci. 68 (8), 815-819.

27. Zorman, T.; Heydrickx, M.; Uzunovic-Kamberovic, S.; Smole-Mozina, S. (2006). Genotyping of Campylobacter coli and C. jejuni from retail chicken meat and humans with campylobacteriosis in Slovenia and Bosnia and Herzegovina. Int .J. Food Microbiol. 110 (1), 24 -33. 